\title{
Genetic variants in the acylphosphatase 2 gene and the risk of breast cancer in a Han Chinese population
}

\author{
Fuli Zhang ${ }^{1, *}$, Yan Zhang ${ }^{1,}{ }^{*}$, Zhiping Deng ${ }^{2}$, Pengcheng $X \mathrm{u}^{3}$, Xiyang Zhang ${ }^{4}$, Tianbo \\ Jin' ${ }^{4,5}$, Qiufang Liú ${ }^{6}$ \\ ${ }^{1}$ Department of Oncology Surgery, Traditional Chinese Medicine Hospital of Xi'an, Xi'an, Shaanxi 710021, China \\ ${ }^{2}$ Department of Breast Surgery, Tumor Hospital of Shaanxi Province, Xi'an 710061, China \\ ${ }^{3}$ Inner Mongolia Medical University, Hohhot 010010, Inner Mongolia, China \\ ${ }^{4}$ School of Life Sciences, Northwest University, Xi'an, Shaanxi 710069, China \\ ${ }^{5}$ Key Laboratory of Resource Biology and Biotechnology, Ministry of Education, Northwest University, Xi'an, Shaanxi 710069, China \\ ${ }^{6}$ Department of Radiotherapy, Tumor Hospital of Shaanxi Province, Xi'an 710061, China \\ "These authors contributed equally to this work
}

Correspondence to: Qiufang Liu, email: qiufangliu@hotmail.com

Keywords: breast cancer, ACYP2, single nucleotide polymorphism, association study

Received: July 28, $2016 \quad$ Accepted: October 19, $2016 \quad$ Published: November 22, 2016

\section{ABSTRACT}

We performed a case-control study to investigate the associations between seven single nucleotide polymorphisms (SNPs) in the acylphosphatase 2 (ACYP2) gene and breast cancer (BC) risk in a Han Chinese population. There were 183 BC cases and 195 healthy controls included in the study. The SNPs were genotyped using the Sequenom MassARRAY platform. Logistic regression (adjusted for age group, body mass index [BMI], and menopause status), was used to evaluate the associations between the various genotypes and BC risk. Statistical analysis revealed that rs12621038 was associated with a decreased risk of BC in the allele (T vs. C: odds ratio [OR] $=0.71$, $95 \%$ confidence interval $[95 \% \mathrm{CI}]=0.52-0.94 ; p=0.016$ ), homozygous (TT vs. CC: $O R=0.47,95 \%$ CI $=0.24-0.85 ; p=0.014)$, dominant $(O R=0.62 ; 95 \%$ $\mathrm{CI}=0.40-0.96 ; p=0.032)$, and additive $(\mathrm{OR}=0.68 ; 95 \% \mathrm{CI}=0.50-0.92 ; p=0.012)$ models. In addition, we found that rs1682111 and rs17045754 were associated with the risk of $B C$ and correlated with recurrence, and that rs6713088 correlated with tumor size. In sum, our findings reveal significant associations between SNPs in the ACYP2 gene and BC risk in a Han Chinese population.

\section{INTRODUCTION}

Breast cancer $(\mathrm{BC})$ is a lethal malignancy that arises in the breast tissue or ducts. It is a major cause of morbidity and mortality in women worldwide [1]. There were an estimated 231,840 new cases of invasive BC among U.S. women in 2015 and 40,290 BC deaths [2]. BC risk factors include age, genetics, family history, younger age at menarche, and older age at menopause $[3,4]$. Approximately $5 \%-10 \%$ of all BC cases are hereditary [5]. Previous studies have identified several genes associated with $\mathrm{BC}$ susceptibility in various populations such as ACYP2, MACC1, BRCA1, BRCA2, PTEN, CHEK2, BACH1, PALB2, RAD50, and TP53. [6-10]. Interestingly, rs11125529 in $A C Y P 2$ was associated with a risk of hormone-related cancers (breast, ovarian, and prostate) in a European population, [11, 12].
The ACYP 2 gene is located on human chromosome 2 (2p16.2). This gene encodes an acylphosphatase (AcPase) that hydrolyzes the phosphoenzyme intermediates of various membrane pumps (e.g. the sarcoplasmic reticulum $\mathrm{Ca}^{2+} / \mathrm{Mg}^{2+}$-ATPase found in skeletal muscle) $[13,14]$. It also has a potential role in maintaining $\mathrm{Ca}^{2+}$ homeostasis [15]. The primary functions of $A C Y P 2$ include pyruvate metabolism [11], cell differentiation [16-18], and programmed cell death (apoptosis) [19]. Apoptosis is involved in a variety of biological processes including embryonic development, immune system regulation, tissue homeostasis, and tumor suppression. Therefore, $A C Y P 2$ may regulate apoptosis $[19,20]$, and mutations in $A C Y P 2$ may promote tumorigenesis.

Previous studies have demonstrated that overexpression of $A C Y P 2$ promotes the differentiation of SH-SY5Y neuroblastoma cells [21]. Additionally, ACYP2 
Table 1: Distributions of select variables in breast cancer patients and healthy controls

\begin{tabular}{|c|c|c|c|c|}
\hline Characteristics & & Cases & Controls & $p$ value \\
\hline Number & & 183 & 195 & \\
\hline Age $($ mean $\pm \mathrm{SD})$ & & $46.4 \pm 9.38$ & $45.35 \pm 6.89$ & $0.218^{\mathrm{a}}$ \\
\hline $\mathrm{BMI}, \mathrm{kg} / \mathrm{m}^{2}($ mean $\pm \mathrm{SD})$ & & $23.08 \pm 3.00$ & $22.53 \pm 2.55$ & $0.056^{\mathrm{a}}$ \\
\hline \multirow[t]{3}{*}{ Menopause status } & & & & $0.716^{\mathrm{b}}$ \\
\hline & Premenopausal & 115 & 119 & \\
\hline & Postmenopausal & 68 & 76 & \\
\hline \multirow[t]{2}{*}{ Age of menarche } & $\leq 12$ & 25 & & \\
\hline & $>12$ & 158 & & \\
\hline \multirow[t]{2}{*}{ Tumor size $(\mathrm{cm})$} & $\leq 3$ & 94 & & \\
\hline & $>3$ & 89 & & \\
\hline \multirow[t]{2}{*}{ Breastfeeding duration (month) } & $\leq 6$ & 12 & & \\
\hline & $>6$ & 158 & & \\
\hline \multirow{2}{*}{ Primiparous age } & $<30$ & 170 & & \\
\hline & $\geq 30$ & 6 & & \\
\hline \multirow[t]{2}{*}{ Procreative times } & $<1$ & 142 & & \\
\hline & $\geq 1$ & 33 & & \\
\hline \multirow[t]{2}{*}{ Clinical stage } & $\overline{\mathrm{I}} / \mathrm{II}$ & 153 & & \\
\hline & III/IV & 48 & & \\
\hline \multirow[t]{2}{*}{ LN metastasis } & Negative & 105 & & \\
\hline & Positive & 75 & & \\
\hline \multirow[t]{2}{*}{ Family tumor history } & Negative & 156 & & \\
\hline & Positive & 27 & & \\
\hline \multirow[t]{2}{*}{ Incipient or recurrent } & Incipient & 109 & & \\
\hline & Recurrent & 73 & & \\
\hline \multirow[t]{2}{*}{ ER } & Negative & 60 & & \\
\hline & Positive & 123 & & \\
\hline \multirow[t]{2}{*}{ PR } & Negative & 75 & & \\
\hline & Positive & 108 & & \\
\hline \multirow[t]{3}{*}{ Tumor location } & Left & 84 & & \\
\hline & Right & 97 & & \\
\hline & Both & 2 & & \\
\hline \multirow[t]{2}{*}{ Tumor type } & Infiltrating ductal carcinoma & 165 & & \\
\hline & Other & 18 & & \\
\hline \multirow[t]{2}{*}{ Fertility status } & Negative & 4 & & \\
\hline & Positive & 116 & & \\
\hline
\end{tabular}

$\mathrm{LN}$ metastasis $=$ lymph node metastasis; $\mathrm{ER}=$ estrogen receptor; $\mathrm{PR}=$ progesterone receptor.

$\mathrm{BMI}=$ body mass index.

${ }^{a} p$ value was calculated by $t$ test.

${ }^{\mathrm{b}} p$ value was calculated by Pearson's $\mathrm{x}^{2}$ test.

was associated with colorectal cancer metastasis [22].

However, few studies have investigated the association between $A C Y P 2$ and $\mathrm{BC}$ risk, particularly in a Chinese population. Here, we investigated whether seven SNPs in $A C Y P 2$ (rs6713088, rs12621038, rs1682111, rs843752, rs 10439478, rs17045754, and rs843720) were associated with $\mathrm{BC}$ risk in a Han Chinese population. Our data indicate common SNPs in $A C Y P 2$ are associated with $\mathrm{BC}$ susceptibility.

\section{RESULTS}

A total of 183 patients with $\mathrm{BC}$ and 195 healthy individuals were enrolled in this study. The clinicopathological characteristics of the cases and controls are shown in Table 1. The average age was $46.40 \pm 9.38$ years and $45.35 \pm 6.90$ years in the case and control populations, respectively. The menopausal status $(p=0.716)$ and body mass index (BMI) $(p=0.056)$ 
Table 2: Allele frequencies in cases and controls, and odds ratio estimates for breast cancer risk

\begin{tabular}{llccccccccc}
\hline \multicolumn{1}{c}{ SNP ID } & Gene & $\begin{array}{c}\text { Chromosome } \\
\text { position }\end{array}$ & $\begin{array}{c}\text { Base } \\
\text { change }\end{array}$ & $\begin{array}{c}\text { MAF- } \\
\text { cases }\end{array}$ & $\begin{array}{c}\text { MAF- } \\
\text { controls }\end{array}$ & $\begin{array}{c}\text { HWE test } \\
\boldsymbol{p} \text {-value }\end{array}$ & OR & $\mathbf{9 5 \%}$ CI & $\boldsymbol{p}$ \\
\hline rs6713088 & $A C Y P 2$ & $2 \mathrm{p} 16.2$ & $\mathrm{G} / \mathrm{C}$ & 0.410 & 0.428 & 0.884 & 0.929 & 0.695 & 1.241 & 0.617 \\
$\mathrm{rs} 12621038$ & $A C Y P 2$ & $2 \mathrm{p} 16.2$ & $\mathrm{~T} / \mathrm{C}$ & 0.383 & 0.469 & 0.666 & 0.701 & 0.524 & 0.936 & $\mathbf{0 . 0 1 6 *}$ \\
$\mathrm{rs} 1682111$ & $A C Y P 2$ & $2 \mathrm{p} 16.2$ & $\mathrm{~A} / \mathrm{T}$ & 0.322 & 0.256 & 1.000 & 1.380 & 1.006 & 1.892 & $\mathbf{0 . 0 4 5 *}$ \\
rs843752 & $A C Y P 2$ & $2 \mathrm{p} 16.2$ & $\mathrm{G} / \mathrm{T}$ & 0.303 & 0.300 & 0.305 & 1.016 & 0.744 & 1.386 & 0.922 \\
$\mathrm{rs} 10439478$ & $A C Y P 2$ & $2 \mathrm{p} 16.2$ & $\mathrm{C} / \mathrm{A}$ & 0.385 & 0.441 & 0.193 & 0.795 & 0.595 & 1.063 & 0.122 \\
rs17045754 & $A C Y P 2$ & $2 \mathrm{p} 16.2$ & $\mathrm{C} / \mathrm{G}$ & 0.145 & 0.205 & 0.508 & 0.656 & 0.448 & 0.960 & $\mathbf{0 . 0 2 9 *}$ \\
rs843720 & $A C Y P 2$ & $2 \mathrm{p} 16.2$ & $\mathrm{G} / \mathrm{T}$ & 0.295 & 0.305 & 0.866 & 0.953 & 0.698 & 1.301 & 0.763 \\
\hline
\end{tabular}

$\mathrm{MAF}=$ minor allele frequency; HWE $=$ Hardy-Weinberg Equilibrium.

$\mathrm{OR}=$ odds ratio; $95 \% \mathrm{CI}=95 \%$ confidence interval.

$* p \leq 0.05$ indicates statistical significance.

Table 3: Genotypes among the cases and controls and the associations with breast cancer risk (adjusted for age group, body mass index, and menopause status)

\begin{tabular}{cccccccc}
\hline \multicolumn{1}{c}{ SNP } & Genotype & Controls & Cases & OR (95\% CI) & 95\% CI & p \\
\hline rs6713088 & $\mathrm{C} / \mathrm{C}$ & 64 & 63 & & & & 1.000 \\
& $\mathrm{C} / \mathrm{G}$ & 94 & 90 & 1.00 & 0.63 & 1.58 & 0.993 \\
& $\mathrm{G} / \mathrm{G}$ & 36 & 30 & 0.88 & 0.48 & 1.60 & 0.667 \\
rs12621038 & $\mathrm{C} / \mathrm{C}$ & 53 & 67 & & & & 1.000 \\
& $\mathrm{C} / \mathrm{T}$ & 101 & 92 & 0.68 & 0.43 & 1.08 & 0.105 \\
& $\mathrm{~T} / \mathrm{T}$ & 41 & 24 & 0.46 & 0.24 & 0.85 & $\mathbf{0 . 0 1 4}$ \\
rs1682111 & $\mathrm{T} / \mathrm{T}$ & 108 & 81 & & & & 1.000 \\
& $\mathrm{~T} / \mathrm{A}$ & 74 & 86 & 1.56 & 1.01 & 2.39 & $\mathbf{0 . 0 4 3}$ \\
& $\mathrm{A} / \mathrm{A}$ & 13 & 16 & 1.67 & 0.75 & 3.70 & 0.209 \\
rs843752 & $\mathrm{T} / \mathrm{T}$ & 92 & 67 & & & & 1.000 \\
& $\mathrm{~T} / \mathrm{G}$ & 89 & 91 & 0.84 & 0.55 & 1.29 & 0.418 \\
& $\mathrm{G} / \mathrm{G}$ & 14 & 25 & 1.33 & 0.62 & 2.84 & 0.465 \\
rs10439478 & $\mathrm{A} / \mathrm{A}$ & 56 & 67 & & & & 1.000 \\
& $\mathrm{~A} / \mathrm{C}$ & 105 & 91 & 0.71 & 0.45 & 1.13 & 0.147 \\
& $\mathrm{C} / \mathrm{C}$ & 33 & 25 & 0.64 & 0.34 & 1.20 & 0.163 \\
rs17045754 & $\mathrm{G} / \mathrm{G}$ & 121 & 135 & & & & 1.000 \\
& $\mathrm{G} / \mathrm{C}$ & 68 & 43 & 0.58 & 0.37 & 0.92 & $\mathbf{0 . 0 2 0}$ \\
& $\mathrm{C} / \mathrm{C}$ & 6 & 5 & 0.78 & 0.23 & 2.68 & 0.693 \\
rs843720 & $\mathrm{T} / \mathrm{T}$ & 93 & 90 & & & & 1.000 \\
& $\mathrm{~T} / \mathrm{G}$ & 85 & 78 & 0.93 & 0.60 & 1.42 & 0.725 \\
& $\mathrm{G} / \mathrm{G}$ & 17 & 15 & 0.86 & 0.40 & 1.85 & 0.700 \\
\hline
\end{tabular}

$\mathrm{CI}=$ confidence interval; $\mathrm{OR}=$ odds ratio; $\mathrm{SNP}=$ single nucleotide polymorphism.

$* p \leq 0.05$ indicates statistical significance.

distributions were similar between the $\mathrm{BC}$ patients and healthy controls. The basic information for the analyzed SNPs (chromosomal position, gene, allele, HardyWeinberg Equilibrium [HWE] test results, and minor allele frequency [MAF]) are shown in Table 2. The SNPs were in agreement with HWE $(p>0.05)$. The SNP call rate threshold was $98 \%$.
The genotype counts for SNPs in $A C Y P 2$ (rs6713088, rs12621038, rs1682111, rs843752, rs10439478, rs17045754, and rs843720) are shown in Table 3. The frequency distribution of rs12621038 genotypes in $\mathrm{BC}$ patients was the following: $\mathrm{CC}, \mathrm{CT}$, and TT. The TT genotype was associated with a decreased risk of $\mathrm{BC}$ compared to the $\mathrm{CC}$ genotype (TT vs. CC: 
$\mathrm{OR}=0.47,95 \% \mathrm{CI}=0.24-0.85 ; p=0.014)$. Additionally, the GC genotype of rs17045754 was associated with a decreased risk of $\mathrm{BC}$ compared to the GG genotype ( $\mathrm{GC}$ vs. GG: $\mathrm{OR}=0.58,95 \% \mathrm{CI}=0.37-0.92 ; p=0.020$ ). Finally, the AT genotype of rs1682111 was associated with an increased risk of $\mathrm{BC}$ compared to the TT genotype (AT vs. TT: $\mathrm{OR}=1.56,95 \% \mathrm{CI}=1.01-2.39 ; p=0.043$ ).

We next analyzed the associations between SNPs in $A C Y P 2$ and patient clinicopathological features including age of menarche, tumor size $(\mathrm{cm})$, duration of breast feeding (months), primiparous age, procreative times), clinical stage, lymph node (LN) metastasis, family history of cancer, incipient or recurrent tumor, estrogen receptor (ER) status, progesterone receptor (PR) status, tumor type, and fertility status. The results for positive associations are shown in Table 4. The GC + CC genotype of rs6713088 was present at a lower frequency in the tumor size $>3 \mathrm{~cm}$ cases $(\mathrm{OR}=0.47,95 \% \mathrm{CI}=0.26-0.91 ; p=0.02)$ than the CC genotype. Moreover, the GC genotype of rs 17045754 was present at a higher frequency in patients with $\mathrm{BC}$ recurrence $(\mathrm{OR}=2.06,95 \% \mathrm{CI}=1.05-4.034 ; p=0.04)$ than the GG + CC genotype. There were no significant differences between the other clinicopathological features in the cases and controls $(p>0.05)$.

Three genetic models (dominant, recessive, and additive) were used to analyze the associations between the SNPs and BC risk. The results of logistic regression analyses are shown in Table 5. We assumed that the minor allele of each SNP was a risk allele compared to wild type. We found that the minor allele T of rs12621038 was associated with a decreased risk of $\mathrm{BC}$ in the dominant
$(\mathrm{OR}=0.62 ; 95 \% \mathrm{CI}=0.40-0.96 ; p=0.032)$ and additive $(\mathrm{OR}=0.68 ; 95 \% \mathrm{CI}=0.50-0.92 ; p=0.012)$ models. Similar results were obtained for rs17045754. It was associated with a decreased risk of BC in both the dominant $(p=0.022)$ and additive $(p=0.041)$ models. The A allele of rs1682111 was associated with an increased risk of BC risk in the dominant $(\mathrm{OR}=1.57 ; 95 \% \mathrm{CI}=1.04-2.37$; $p=0.031)$ and additive $(\mathrm{OR}=1.41 ; 95 \% \mathrm{CI}=1.01-1.95$; $p=0.042$ ) models. We performed a Bonferroni correction for multiple comparisons. However, none of the associations were statistically significant after correction.

Wald tests were performed using an unconditional multivariate regression analysis to assess the associations between SNP haplotypes and BC risk. Interestingly, we determined that $A C Y P 2$ haplotypes were associated with $\mathrm{BC}$ risk. We identified one haplotype block comprised of rs1682111 and rs843752 (Table 6, Figure 1). The AT haplotype was associated with an increased risk of $\mathrm{BC}$ $(\mathrm{OR}=1.41 ; 95 \% \mathrm{CI}=1.01-1.95 ; p=0.042)$, while the TT haplotype was associated with a decreased risk of $\mathrm{BC}(\mathrm{OR}=0.73 ; 95 \% \mathrm{CI}=0.53-0.99 ; p=0.045)$ after adjustment for age, BMI, and menopause status.

\section{DISCUSSION}

We investigated associations between seven SNPs in the $A C Y P 2$ gene and $\mathrm{BC}$ risk in a Han Chinese population. Our results indicate that rs12621038, rs17045754, and rs1682111 are associated with the risk of BC. These findings were confirmed in an analysis of two independent patient populations. Two SNPs (rs12621038 and

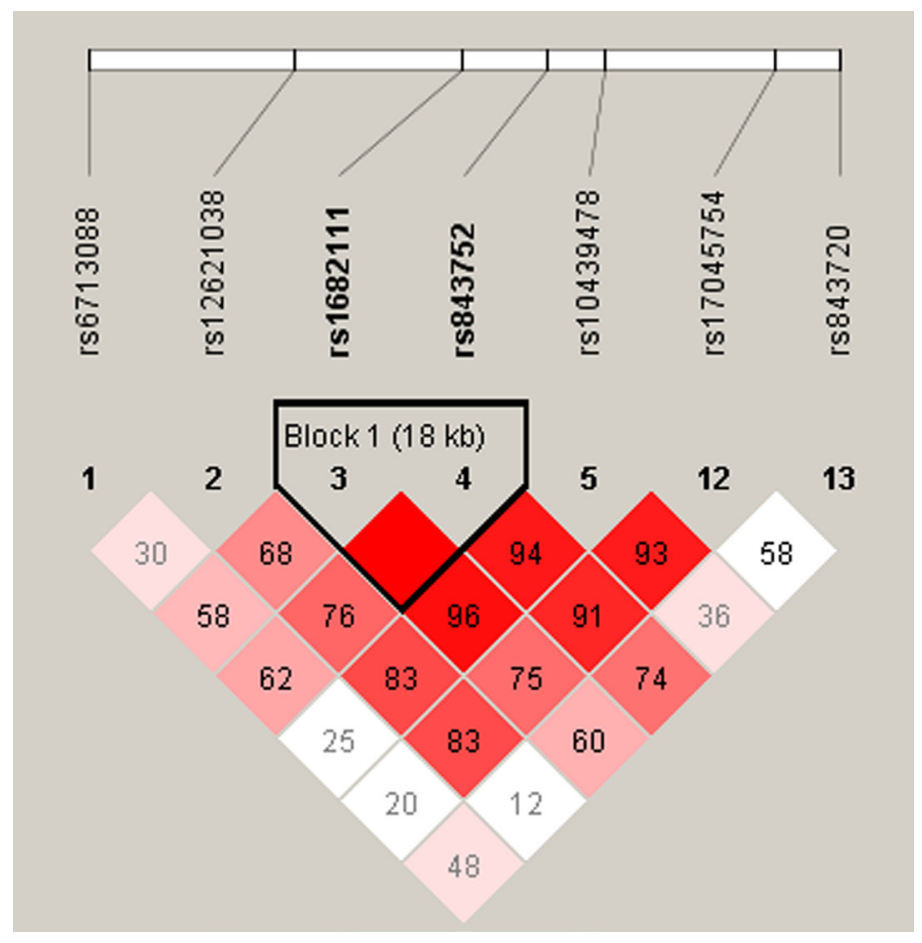

Figure 1: Haplotype block map for the seven SNPs analyzed in the $A C Y P 2$ gene. 


\begin{tabular}{|c|c|c|c|c|c|c|c|c|c|c|c|c|c|c|c|}
\hline \multirow{2}{*}{ Variables } & \multicolumn{5}{|c|}{ rs6713088 } & \multicolumn{5}{|c|}{ rs1682111 } & \multicolumn{5}{|c|}{ rs17045754 } \\
\hline & $\mathrm{CC}$ & $\mathbf{G G}+\mathbf{G C}$ & $p$ & $\mathbf{O R}^{\Phi}$ & $95 \%$ CI & TT & $\mathbf{T A}+\mathbf{A A}$ & $p$ & $\mathbf{O R}^{\Phi}$ & $95 \%$ CI & GG & $\mathbf{G C}+\mathbf{C C}$ & $p$ & $\mathbf{O R}^{\Phi}$ & $95 \%$ CI \\
\hline \multicolumn{16}{|l|}{ Age of menarche } \\
\hline$\leq 12$ & 8 & 17 & 0.783 & 1.14 & $0.05-2.79$ & 10 & 15 & 0.231 & 1.22 & $0.52-2.89$ & 21 & 4 & 0.218 & 0.49 & $0.16-1.52$ \\
\hline$>12$ & 55 & 103 & & 1.00 & (reference) & 87 & 71 & & 1.00 & (reference) & 114 & 44 & & 1.00 & (reference) \\
\hline \multicolumn{16}{|l|}{ Tumor size $(\mathrm{cm})$} \\
\hline$\leq 3$ & 25 & 69 & & 1.00 & (reference) & 44 & 50 & & 1.00 & (reference) & 70 & 24 & & 1.00 & (reference) \\
\hline$>3$ & 38 & 51 & $0.023 *$ & 0.47 & $0.26-0.91$ & 37 & 52 & 0.476 & 1.24 & $0.69-2.22$ & 65 & 24 & 0.826 & 1.08 & $0.56-2.08$ \\
\hline \multicolumn{16}{|l|}{ Breast feeding duration (month) } \\
\hline$\leq 6$ & 1 & 11 & 0.089 & 6.04 & $0.76-48.00$ & 6 & 6 & 0.671 & 0.78 & $0.24-2.51$ & 10 & 2 & 0.481 & 0.57 & $0.12-2.71$ \\
\hline$>6$ & 56 & 102 & & 1.00 & (reference) & 69 & 89 & & 1.00 & (reference) & 117 & 41 & & 1.00 & (reference) \\
\hline \multicolumn{16}{|l|}{ Primiparous age } \\
\hline$<30$ & 59 & 111 & & 1.00 & (reference) & 72 & 98 & & 1.00 & (reference) & 128 & 42 & & 1.00 & (reference) \\
\hline$\geq 30$ & 1 & 5 & 0.377 & 0.38 & $0.04-3.30$ & 6 & 0 & -- & -- & -- & 4 & 2 & 0.634 & 0.66 & $0.12-3.71$ \\
\hline \multicolumn{16}{|l|}{ Procreative times } \\
\hline$<1$ & 44 & 98 & 0.059 & 2.10 & $0.97-4.53$ & 62 & 80 & 0.852 & 1.08 & $0.50-2.30$ & 108 & 34 & 0.449 & 0.72 & $0.41-1.67$ \\
\hline$\geq 1$ & 16 & 17 & & 1.00 & (reference) & 15 & 18 & & 1.00 & (reference) & 23 & 10 & & 1.00 & (reference) \\
\hline \multicolumn{16}{|l|}{ Clinical stage } \\
\hline $\mathrm{I} / \mathrm{II}$ & 46 & 89 & 0.866 & 0.94 & $0.47-1.88$ & 54 & 81 & 0.053 & 0.52 & $0.27-1.01$ & 98 & 37 & 0.544 & 0.79 & $0.36-1.70$ \\
\hline III/IV & 17 & 31 & & 1.00 & (reference) & 27 & 21 & & 1.00 & (reference) & 37 & 11 & & 1.00 & (reference) \\
\hline \multicolumn{16}{|l|}{ LN metastasis } \\
\hline Negative & 38 & 67 & & 1.00 & (reference) & 49 & 56 & & 1.00 & (reference) & 77 & 28 & & 1.00 & (reference) \\
\hline Positive & 23 & 52 & 0.441 & 1.28 & $0.68-2.41$ & 31 & 44 & 0.478 & 1.24 & $0.64-2.26$ & 55 & 20 & 1.000 & 1.00 & $0.51-1.95$ \\
\hline \multicolumn{16}{|l|}{ Family tumor history } \\
\hline Negative & 53 & 103 & & 1.00 & (reference) & 72 & 84 & & 1.00 & (reference) & 116 & 40 & & 1.00 & (reference) \\
\hline Positive & 10 & 17 & 0.757 & 0.88 & $0.37-2.04$ & 9 & 18 & 0.219 & 1.71 & $0.73-4.05$ & 19 & 8 & 0.664 & 1.22 & $0.50-3.01$ \\
\hline \multicolumn{16}{|l|}{ Incipient or recurrent } \\
\hline Incipient & 40 & 69 & & 1.00 & (reference) & 39 & 70 & & 1.00 & (reference) & 87 & 22 & & 1.00 & (reference) \\
\hline Recurrent & 23 & 50 & 0.471 & 1.26 & $0.67-2.36$ & 28 & 45 & 0.724 & 0.90 & $0.49-1.65$ & 48 & 25 & $0.035^{*}$ & 2.06 & $1.05-4.04$ \\
\hline \multicolumn{16}{|l|}{ ER } \\
\hline Negative & 25 & 35 & & 1.00 & (reference) & 29 & 31 & & 1.00 & (reference) & 45 & 15 & & 1.00 & (reference) \\
\hline Positive & 38 & 85 & 0.151 & 1.60 & $0.84-3.03$ & 52 & 71 & 0.439 & 1.28 & $0.69-2.37$ & 90 & 33 & 0.791 & 1.10 & $0.54-2.23$ \\
\hline \multicolumn{16}{|l|}{ PR } \\
\hline Negative & 29 & 46 & & 1.00 & (reference) & 35 & 40 & & 1.00 & (reference) & 55 & 20 & & 1.00 & (reference) \\
\hline Positive & 34 & 74 & 0.315 & 1.37 & $0.74-2.54$ & 46 & 62 & 0.585 & 1.18 & $0.65-2.13$ & 80 & 28 & 0.911 & 0.96 & $0.49-1.88$ \\
\hline \multicolumn{16}{|l|}{ Tumor type } \\
\hline Infiltrating ductal carcinoma & 56 & 109 & 0.675 & 1.24 & $0.46-3.37$ & 75 & 90 & 0.330 & 0.60 & $0.22-1.68$ & 120 & 45 & 0.338 & 1.88 & $0.52-6.79$ \\
\hline Other & 7 & 11 & & 1.00 & (reference) & 6 & 12 & & 1.00 & (reference) & 15 & 3 & & 1.00 & (reference) \\
\hline \multicolumn{16}{|l|}{ Fertility status } \\
\hline Negative & 3 & 4 & 0.634 & 0.69 & $0.15-3.18$ & 3 & 4 & 0.939 & 1.06 & $0.23-4.88$ & 3 & 4 & 0.077 & 4.00 & $0.86-18.57$ \\
\hline Positive & 60 & 116 & & 1.00 & (reference) & 78 & 98 & & 1.00 & (reference) & 132 & 44 & & 1.00 & (reference) \\
\hline
\end{tabular}

rs17045754) were associated with a decreased risk of BC and one SNP (rs1682111) was associated with increased BC susceptibility. Finally, rs6713088 genotypes were inversely correlated with tumor size, while rs17045754 was correlated with $\mathrm{BC}$ recurrence.

These results deviated from the expected frequency of the $T$ allele in the general population compared to the reported frequency of rs12621038 in the Han Chinese population. The allele frequencies reported by the 1000 Genomes Project are: C-81.4\% and T-19.6\%, while the HapMap project reported the following frequencies: $\mathrm{C}-54.7 \%$ and $\mathrm{T}-45.3 \%$ in a Chinese population. In different Chinese ethnic groups and in Europeans, the genotype frequencies of rs 12621038 vary significantly (C-79.2\% and T-20.8\%). Thus, different ethnic populations exhibit different allele distributions, which can result in altered interactions with environmental effects. 
Table 5: Association between SNPs in $A C Y P 2$ and breast cancer risk in dominant, recessive, and additive models after adjusting for age group, body mass index, and menopause status

\begin{tabular}{lcccccccccccccc}
\hline \multirow{2}{*}{ SNP } & Minor & \multicolumn{3}{c}{ Dominant model } & \multicolumn{4}{c}{ Recessive model } & \multicolumn{4}{c}{ Additive model } \\
\cline { 3 - 14 } & allele & OR & $\mathbf{9 5 \%}$ CI & $\boldsymbol{p}$ & OR & $\mathbf{9 5 \%}$ CI & $\boldsymbol{p}$ & OR & $\mathbf{9 5 \%}$ CI & $\boldsymbol{p}$ \\
\hline rs6713088 & $\mathrm{G}$ & 0.96 & 0.63 & 1.49 & 0.870 & 0.88 & 0.51 & 1.50 & 0.633 & 0.95 & 0.70 & 1.27 & 0.710 \\
rs12621038 & $\mathrm{T}$ & 0.62 & 0.40 & 0.96 & $\mathbf{0 . 0 3 2 *}$ & 0.58 & 0.33 & 1.01 & 0.054 & 0.68 & 0.50 & 0.92 & $\mathbf{0 . 0 1 2 *}$ \\
rs1682111 & $\mathrm{A}$ & 1.57 & 1.04 & 2.37 & $\mathbf{0 . 0 3 1 *}$ & 1.36 & 0.63 & 2.94 & 0.436 & 1.41 & 1.01 & 1.95 & $\mathbf{0 . 0 4 2 *}$ \\
rs843752 & $\mathrm{G}$ & 0.90 & 0.60 & 1.36 & 0.632 & 1.44 & 0.69 & 3.00 & 0.327 & 1.01 & 0.73 & 1.39 & 0.953 \\
rs10439478 & $\mathrm{C}$ & 0.69 & 0.45 & 1.08 & 0.103 & 0.78 & 0.44 & 1.38 & 0.401 & 0.78 & 0.57 & 1.06 & 0.112 \\
rs17045754 & $\mathrm{C}$ & 0.60 & 0.38 & 0.93 & $\mathbf{0 . 0 2 2} *$ & 0.92 & 0.27 & 3.13 & 0.895 & 0.67 & 0.45 & 0.98 & $\mathbf{0 . 0 4 1 *}$ \\
rs843720 & $\mathrm{G}$ & 0.92 & 0.61 & 1.38 & 0.671 & 0.89 & 0.43 & 1.87 & 0.763 & 0.93 & 0.67 & 1.28 & 0.643 \\
\hline
\end{tabular}

$\mathrm{OR}=$ odds ratio $; 95 \% \mathrm{CI}=95 \%$ confidence interval.

${ }^{*} p \leq 0.05$ indicates statistical significance.

Table 6: The associations between $A C Y P 2$ haplotypes and breast cancer risk

\begin{tabular}{|c|c|c|c|c|c|c|c|c|c|c|c|c|}
\hline \multirow{3}{*}{ Gene } & \multirow{2}{*}{ SNP } & \multirow{3}{*}{$\begin{array}{c}\text { Haplotype } \\
\text { TG }\end{array}$} & \multicolumn{2}{|c|}{ Frequency (\%) } & \multicolumn{4}{|c|}{ Crude analysis } & \multicolumn{4}{|c|}{ Adjusted analysis } \\
\hline & & & \multirow{2}{*}{$\frac{\text { Cases }}{0.30}$} & \multirow{2}{*}{$\begin{array}{c}\text { Controls } \\
0.30\end{array}$} & \multirow{2}{*}{$\frac{\text { OR }}{1.02}$} & \multicolumn{2}{|c|}{$95 \% \mathrm{CI}$} & \multirow{2}{*}{$\frac{p}{0.921}$} & \multirow{2}{*}{$\frac{\mathbf{O R}}{1.01}$} & \multicolumn{2}{|c|}{$95 \%$ CI } & \multirow{2}{*}{$\frac{p}{0.953}$} \\
\hline & & & & & & 0.74 & 1.39 & & & 0.73 & 1.39 & \\
\hline \multirow[t]{2}{*}{$A C Y P 2$} & rs1682111|rs843752 & AT & 0.32 & 0.26 & 1.40 & 1.01 & 1.93 & $\mathbf{0 . 0 4 3}^{\&}$ & 1.41 & 1.01 & 1.95 & $0.042^{*}$ \\
\hline & & $\mathrm{TT}$ & 0.37 & 0.44 & 0.72 & 0.53 & 0.99 & $0.042^{\&}$ & 0.73 & 0.53 & 0.99 & $0.045^{\circ}$ \\
\hline
\end{tabular}

$\mathrm{OR}=$ odds ratio $95 \% \mathrm{CI}=95 \%$ confidence interval.

${ }^{\star}$ Crude Analysis.

* Adjusted for age group, BMI, and menopause status.

$p \leq 0.05$ indicates statistical significance.

AcPases are small cytosolic enzymes $(11 \mathrm{kDa})$ that are broadly expressed in vertebrate tissues. They exist in two different isoenzymatic forms: the muscle and organ-common types [23, 24]. Previous studies have demonstrated that AcPase nuclease activity on DNA in an acidic environment plays a role in DNA hydrolysis during apoptosis $[19,25,26]$. AcPases also hydrolyze phosphoenzyme intermediates generated by various membrane pumps [14] and may modulate $\mathrm{Ca}^{2+}$ homeostasis. Calcium can regulate both cell survival and death [27]. Indeed, deregulation of $\mathrm{Ca}^{2+}$ homeostasis is one of the first hallmarks of apoptosis [28]. Cancer cells can evade apoptosis through decreased expression of $\mathrm{Ca}^{2+}$-permeable channels to prevent calcium influx, acquire resistance to prolonged endoplasmic reticulum calcium deficiency, and down-regulate mitochondrial calcium uniporters [29]. AcPase pathways may be altered in various cancers, and overexpression of $A C Y P 2$ could decrease the risk of $\mathrm{BC}$.

There are limited data on the relationship between tumor size and the risk of BC [30]. Recently, Nuyten et al. performed gene expression profiling to identify gene signatures that could predict $\mathrm{BC}$ [31]. We have provided the first evidence that polymorphisms in $A C Y P 2$ are associated with clinical outcomes in BC. Our data indicate that rs6713088 is associated with tumor size and that rs17045754 may be a genetic marker that could be used to predict $\mathrm{BC}$ recurrence.

A limitation of this study was the relatively small dataset, which decreased the statistical power to detect effects for rare SNPs. In addition, the results of our population comparison and logistic regression analysis indicated that none of the SNPs were significantly associated with BMI, menopausal status, or age. However, some studies have demonstrated that heterogeneity between different $\mathrm{BC}$ patient populations and between different $\mathrm{BC}$ therapies can modify the association between BMI and patient outcome. While these factors may confound the associations between genetic variants and $\mathrm{BC}$ to some degree, the relative similarities between our case and control populations indicated any confounding effects were reduced to a minimum. No significant associations were observed between the SNPs and the risk of $\mathrm{BC}$ after Bonferroni correction. This may be due to our relatively small sample size, the SNP selection criteria (minor allele frequency $>5 \%$ ), and inherent weaknesses of the Bonferroni correction itself (the interpretation of the results depends upon the number of comparisons 
Table 7: Primers

\begin{tabular}{clll}
\hline \multicolumn{1}{c}{ SNP_ID } & \multicolumn{1}{c}{ 1st_PCRP } & \multicolumn{1}{c}{ 2nd_PCRP } & UEP_SEQ \\
\hline \multirow{2}{*}{ rs6713088 } & ACGTTGGATGACACA & ACGTTGGATGGTCACC & gaggcCAGAATGGTCCACTAGAGA \\
& CACAGACTCCTTCAC & AAAACACGTAATG & \\
rs12621038 & ACGTTGGATGATTGT & ACGTTGGATGGGCA & ccATTGCCTCAGCTAGACT \\
& GCTAGGCACTTTAGG & TAAGTTTTATTGCCTC & \\
rs1682111 & ACGTTGGATGGAATT & ACGTTGGATGGCCAGT & tgtcATGCAAAATGAAACAGACACTT \\
& GCTGGGTTATTTGC & GGGAATGCAAAATG & \\
rs843752 & ACGTTGGATGTCCTC & ACGTTGGATGGAGACA & cGAGTTTGGGTTTGAGGT \\
& TTTTCAGAAACCTGC & ACATAATGGAGGTC & \\
rs10439478 & ACGTTGGATGTAGCAC & ACGTTGGATGCTACAC & TTGCTGTTTTCCCAGAA \\
& AAGACCTACACTGG & TCTCCAGAGGAATG & \\
rs17045754 & ACGTTGGATGCTGTA & ACGTTGGATGGAAATC & \multirow{2}{*}{ caggTATTCAGCTTCCTAGAGTTA } \\
& AAAGTTCTGGCATGG & AGGGATATTAGTGC & \\
rs843720 & ACGTTGGATGCTTCAC & ACGTTGGATGAGTCAG & cccAATCTGTCTCAGGGTCTT \\
& AACACTCCTGTAAG & AGCTAGACCTCTGG & \\
\hline
\end{tabular}

performed). Multiple independent studies with large sample sizes are required to validate our findings.

\section{MATERIALS AND METHODS}

\section{Patients and samples}

The study participants were either newly diagnosed $\mathrm{BC}$ patients or cancer-free controls (based on history and screening). Participants were recruited from clinics at the First Affiliated Hospital of Xi' an Jiaotong University between August 2013 and December 2015 as part of the Disease Management Project. The inclusion criteria for the $\mathrm{BC}$ group were the following: age $>18$ years of age and histologically confirmed BC. Patients who received chemotherapy or radiotherapy before surgery, or who had another type of cancer were excluded. Cancer-free controls were selected based on physical examinations at the same hospital and were matched with the cases according to race and age (in 5-year age groups). All participants were Han Chinese and were recruited from regions in Northwest China. Participants gave informed consent and completed a personal interview regarding risk factors, medical history, family history, and lifestyle. Blood samples were collected from all participants. The study was approved by the Department of Oncology Surgery at the First Affiliated Hospital of Xi'an Jiaotong University.

\section{SNP selection and genotyping}

We randomly selected seven potentially function SNPs in the ACYP2 gene (rs6713088, rs12621038, rs1682111, rs843752, rs10439478, rs17045754, and rs843720) for analysis. The SNPs were selected based on population and MAF $>5 \%$ using dbSNP (http://www.ncbi. nlm.nih.gov/projects/SNP). These SNPs represented the majority of known common variants in $A C Y P 2$. Genotyping was performed using a Sequenom MassARRAY RS1000 (Sequenom, Inc., San Diego, CA, USA) according to the manufacturer's instructions. Briefly, locus-specific polymerase chain reaction (PCR) amplification was performed and the products purified by addition of shrimp alkaline phosphatase. Single base extension was then performed using primers that annealed immediately upstream of each SNP. Finally, the alleles were determined by mass spectrometry of the extended primers. The primers used for each SNP are listed in Table 7.

\section{Statistical analysis}

Statistical analyses were performed using SPSS version 17.0 for Windows (SPSS, Chicago, IL, USA). Population characteristics were compared using independent t-tests (Levene's test to assess the equality of variances) for continuous variables and Chi-square tests for categorical variables. The PLINK software package (version 1.07) was used to assess possible heterogeneous associations across populations. All populations were tested for HWE. Genotype and allele effects were analyzed using Chi-square tests. ORs and CIs were calculated from the combined results of both populations after adjustment for age, BMI, and menopause status.

\section{CONCLUSIONS}

Our analysis indicates that rs12621038 and rs17045754 in the $A C Y P 2$ gene are associated with a decreased risk of $\mathrm{BC}$ in a Han Chinese population. In contrast, rs1682111 is associated with an increased risk of BC. Given the influence of environmental factors, our results must be validated in larger cohorts, and detailed functional studies are required. 


\section{ACKNOWLEDGMENTS AND FUNDING}

This work was supported by The Shaanxi provincial administration of foreign experts affairs in 2011 to start the class project

\section{CONFLICTS OF INTEREST}

The authors declare that there are no conflicts of interest.

\section{REFERENCES}

1. Gradishar WJ, Anderson BO, Balassanian R, Blair SL, Burstein HJ, Cyr A, Elias AD, Farrar WB, Forero A, Giordano SH, Goetz M, Goldstein LJ, Hudis CA, et al. Breast Cancer Version 2.2015. Journal of the National Comprehensive Cancer Network. 2015; 13:448-475.

2. DeSantis CE, Fedewa SA, Goding Sauer A, Kramer JL, Smith RA, Jemal A. Breast cancer statistics, 2015: Convergence of incidence rates between black and white women. CA: Ca-Cancer J Clin. 2016; 66:31-42.

3. Lichtenstein P, Holm NV, Verkasalo PK, Iliadou A, Kaprio J, Koskenvuo M, Pukkala E, Skytthe A, Hemminki K. Environmental and heritable factors in the causation of cancer - analyses of cohorts of twins from Sweden, Denmark, and Finland. New Engl J Med. 2000; 343:78-85.

4. McTiernan A, Porter P, Potter JD. Breast cancer prevention in countries with diverse resources. Cancer. 2008; 113:2325-2330.

5. Hirotsu Y, Nakagomi H, Sakamoto I, Amemiya K, Oyama T, Mochizuki H, Omata M. Multigene panel analysis identified germline mutations of DNA repair genes in breast and ovarian cancer. Mol Genet Genomics. 2015; 3:459-466.

6. Dai ZJ, Liu XH, Kang HF, Wang XJ, Jin TB, Zhang SQ, Feng T, Ma XB, Wang M, Feng YJ, Liu K, Xu P, Guan HT. Genetic Variation in Metastasis-Associated in Colon Cancer-1 and the Risk of Breast Cancer Among the Chinese Han Population: A STROBE-Compliant Observational Study. Medicine. 2016; 95:e2801.

7. Dai ZJ, Liu XH, Ma YF, Kang HF, Jin TB, Dai ZM, Guan HT, Wang M, Liu K, Dai C, Yang XW, Wang XJ. Association Between Single Nucleotide Polymorphisms in DNA Polymerase Kappa Gene and Breast Cancer Risk in Chinese Han Population: A STROBE-Compliant Observational Study. Medicine. 2016; 95:e2466.

8. Vinod C, Jyothy A, Vijay Kumar M, Raman RR, Nallari P, Venkateshwari A. A Common SNP of IL-10 (-1082A/G) is Associated With Increased Risk of Premenopausal Breast Cancer in South Indian Women. Iranian journal of cancer prevention. 2015; 8:e3434.

9. Easton DF. How many more breast cancer predisposition genes are there. Breast Cancer Res. 1999; 1:14-17.
10. Pharoah PD, Antoniou A, Bobrow M, Zimmern RL, Easton DF, Ponder BA. Polygenic susceptibility to breast cancer and implications for prevention. Nat Genet. 2002; 31:33-36.

11. Yu WS, Jeong SJ, Kim JH, Lee HJ, Song HS, Kim MS, Ko E, Lee HJ, Khil JH, Jang HJ, Kim YC, Bae H, Chen $\mathrm{CY}$, et al. The genome-wide expression profile of 1,2,3,4,6-penta-O-galloyl-beta-D-glucose-treated MDAMB-231 breast cancer cells: molecular target on cancer metabolism. Mol Cells. 2011; 32:123-132.

12. Pooley KA, Bojesen SE, Weischer M, Nielsen SF, Thompson D, Amin Al Olama A, Michailidou K, Tyrer JP, Benlloch S, Brown J, Audley T, Luben R, Khaw K-T, et al. A genome-wide association scan (GWAS) for mean telomere length within the COGS project: identified loci show little association with hormone-related cancer risk. Hum Mol Genet. 2013.

13. Nediani C, Fiorillo C, Marchetti E, Pacini A, Liguri G, Nassi P. Stimulation of cardiac sarcoplasmic reticulum calcium pump by acylphosphatase. Relationship to phospholamban phosphorylation. J Biol Chem. 1996; 271:19066-19073.

14. Nediani C, Celli A, Fiorillo C, Ponziani V, Giannini L, Nassi P. Acylphosphatase interferes with SERCA2a-PLN association. Biochem Bioph Res Co. 2003; 301:948-951.

15. Degl'Innocenti D, Marzocchini R, Rosati F, Cellini E, Raugei G, Ramponi G. Acylphosphatase expression during macrophage differentiation and activation of U-937 cell line. Biochimie. 1999; 81:1031-1035.

16. Fiaschi T, Chiarugi P, Veggi D, Raugei G, Ramponi G. The inhibitory effect of the $5^{\prime}$ untranslated region of muscle acylphosphatase mRNA on protein expression is relieved during cell differentiation. FEBS lett. 2000; 473:42-46.

17. Liguri G, Nassi P, Degl'Innocenti D, Tremori E, Nediani C, Berti A, Ramponi G. Acylphosphatase levels of human erythrocytes during cell ageing. Mech Ageing Dev. 1987; 39:59-67.

18. Chiarugi P, Degl'Innocenti D, Taddei L, Raugei G, Berti A, Rigacci S, Ramponi G. Acylphosphatase is involved in differentiation of K562 cells. Cell Death Differ. 1997; 4:334-340.

19. Giannoni E, Cirri P, Paoli P, Fiaschi T, Camici G, Manao G, Raugei G, Ramponi G. Acylphosphatase is a strong apoptosis inducer in HeLa cell line. Molecular cell biology research communications. 2000; 3:264-270.

20. Nediani C, Celli A, Formigli L, Perna AM, Fiorillo C, Ponziani V, Ibba-Manneschi L, Zecchi-Orlandini S, Nosi D, Liguri G, Modesti PA, Nassi P. Possible role of acylphosphatase, Bcl-2 and Fas/Fas-L system in the early changes of cardiac remodeling induced by volume overload. Biochimica et Biophysica Acta (BBA) - Molecular Basis of Disease. 2003; 1638:217-226.

21. Cecchi C, Liguri G, Fiorillo C, Bogani F, Gambassi M, Giannoni E, Cirri P, Baglioni S, Ramponi G. 
Acylphosphatase overexpression triggers SH-SY5Y differentiation towards neuronal phenotype. Cellular and molecular life sciences. 2004; 61:1775-1784.

22. Riley HD, Macnab J, Farrell TJ, Cohn K. The expression of acylphosphatase is associated with the metastatic phenotype in human colorectal tumors. Carcinogenesis. 1997; 18:2453-2455.

23. Stefani M, Taddei N, Ramponi G. Insights into acylphosphatase structure and catalytic mechanism. Cell Mol Life Sci. 1997; 53:141-151.

24. Mizuno Y, Kanesaka Y, Fujita H, Minowa O, Shiokawa H. The primary structure of two molecular species of porcine organ-common type acylphosphatase. J Biochem. 1991; 110:790-794.

25. Peitsch MC, Polzar B, Stephan H, Crompton T, MacDonald HR, Mannherz HG, Tschopp J. Characterization of the endogenous deoxyribonuclease involved in nuclear DNA degradation during apoptosis (programmed cell death). The EMBO journal. 1993; 12:371-377.

26. Barry MA, Eastman A. Identification of deoxyribonuclease II as an endonuclease involved in apoptosis. Arch Biochem Biophys. 1993; 300:440-450.
27. Hajnóczky G, Davies E, Madesh M. Calcium signaling and apoptosis. Biochem Bioph Res Co. 2003; 304:445-454.

28. Sawant MA, Dasgupta A, Lavhale MS, Sitasawad SL. Novel triterpenoid AECHL-1 induces apoptosis in breast cancer cells by perturbing the mitochondria-endoplasmic reticulum interactions and targeting diverse apoptotic pathways. Biochimica et biophysica acta. 2016; 1860:1056-1070.

29. Pinton P, Giorgi C, Siviero R, Zecchini E, Rizzuto R. Calcium and apoptosis: ER-mitochondria $\mathrm{Ca} 2+$ transfer in the control of apoptosis. Oncogene. 2008; 27:6407-6418.

30. Nguyen PL, Taghian AG, Katz MS, Niemierko A, Abi Raad RF, Boon WL, Bellon JR, Wong JS, Smith BL, Harris JR. Breast cancer subtype approximated by estrogen receptor, progesterone receptor, and HER-2 is associated with local and distant recurrence after breast-conserving therapy. J Clin Oncol. 2008; 26:2373-2378.

31. Nuyten DSA, Kreike B, Hart AAM, Chi J-T, Sneddon JB, Wessels LFA, Peterse HJ, Bartelink H, Brown PO, Chang HY and van de Vijver MJ. Breast Cancer Res. 2006; 8:R62. 